九州大学学術情報リポジトリ

Kyushu University Institutional Repository

\title{
Phylogenetic study on Cucurbita species by means of esterase zymogram
}

\section{Eguchi, Hiromi}

Biotron Institute, Kyushu University

Matsui, Tsuyoshi

Biotron Institute, Kyushu University

https://doi.org/10.5109/22792

出版情報 : 九州大学大学院農学研究院紀要. 15 (3)，pp. 345-353，1969-07. Kyushu University バージョン：

権利関係 : 
Journal of the Faculty of Agriculture, Kyushu University, Vol. 15, No. 3

July 30,1969

\section{Phylogenetic study on Cucurbita species by means of esterase zymogram}

\section{Hiromi EGUCHI* and Tsuyoshi MATSUI*}

\section{Introduction}

There exist large numbers of species in the genus Cucurbita. In those species, Cucurbita moschata Duch., C. maxima Duch., and C. pepo L. are the most useful species as vegetables, fodders, and as grafting stock for watermelon, cucumber and melon. The taxonomy of those cultivars has been demanded for the progress of the breeding. In addition to the morphological taxonomy, some trials have been attempted on the cytogenetical ground. However, the difficult nature of cytogenetical work with Cucurbita species has mititated against the adequate genome analysis. As one of the techniques for biochmical approach towards taxonomic and phylogenetic problem for those cultivars, comparative zymogram (Hunter and Markert, 1957) for esterases contained in the seedlings was employed in this experiment, applying the working hypotheses obtained in the previous experiment on Brassica species.

\section{Materials and methods}

Cucurbita species used were listed in Table 1 . Seeds were sown on sands, and seedlings were sampled 3 days after germination. Fifty gm of the cotyledonary seedlings was frozen at $-20^{\circ} \mathrm{C}$ and homogenized in $30 \mathrm{ml}$ of $\mathrm{M} / 30$ phosphate buffer of $\mathrm{pH} \mathrm{7.0.} \mathrm{The} \mathrm{homogenate} \mathrm{was} \mathrm{ultra-}$ centrifuged at $145,000 \times \mathrm{g}$ to remove cell-debris and nuclei.

zymo-

* Biotron Institute, Kyushu University, Fukuoka. 
Table 1. Cucurbita species and the horticultural varieties used in the experiments.

\begin{tabular}{clc}
\hline Species & \multicolumn{1}{c}{ Horticultural variety } & Exp. No. \\
\cline { 2 - 3 } C. moschata Duch. & Shiro-kikuza & 1 \\
$\prime \prime$ & Aizu-wase & 2 \\
$"$ & Hyuga No. 14 & 3 \\
" & Mike-kado & 4 \\
C. maxima Duch. & Butter cup & 5 \\
" & Hoko-aokawa-amaguri & 6 \\
" & Delicious & 7 \\
" pepo L. & Nishiki-kanro & 8 \\
" & Table Queen & 9 \\
" & Pumpkin & 10 \\
" & Large Pumpkin & 11 \\
\hline
\end{tabular}

gram. Each gel medium for the electrophoresis was prepared with 0.7 gm of agar, and $2.0 \mathrm{gm}$ of polyvinylpyrrolidone (Ogita, 1962) in $100 \mathrm{ml}$ of $\mathrm{M} / 50$ phosphate buffer of $\mathrm{pH}$ 7.0. Agar-gel plates were made $2 \mathrm{~mm}$ in thickness and supported by grass plate $(120 \mathrm{~mm} \times 165 \mathrm{~mm})$. The lyophilized extract was restored with deionized water and a piece of filter paper $(1.5 \mathrm{~mm} \times 12.0 \mathrm{~mm})$ was saturated with the extract, and was placed on the agar-gel plate. The extract diffused from the filter paper into agar-gel. After 40 minutes, the filter paper was removed and the extract in agar-gel plate was exposed to the stabilized voltage of $20 \mathrm{~V} / \mathrm{cm}$ at $0^{\circ} \mathrm{C} \sim 5^{\circ} \mathrm{C}$ for 120 minutes. After the electrophoretic separation, 1 per cent solution of $\beta$-naphthyl acetate in acetone was sprayed on the surface of the agar-gel as the substrate of esterases. The agargel plate was incubated at $35^{\circ} \mathrm{C}$ for 30 minutes. The substrate, $\beta$ naphthyl acetate, diffused into the agar gel and was hydrolyzed by each esterase separated electrophoretically at individual location on an agargel plate. Naphthanil diazo blue $B$ was used as the dye coupler.

\section{Results and discussion}

As shown in Fig. 1, five bands were discriminated in C. moschata and were designated as $\mathrm{J} 1 \sim \mathrm{J} 5$. The $\mathrm{J} 1$ migrated towards anode. The J2 band was detected in C. moschata "Aizu-wase" only. The intensity of the J5 band of "Mike-kado" was weaker than that of the other forms of C. moschata. No differences among four typical forms of C. moschata could be observed in electrophoretic mobilities of the esterase bands, 
But five bands designated as $\mathrm{K} 1 \sim \mathrm{K} 5$ were found in $\mathrm{C}$. maxima. The K1 band migrated slowly toward cathode, and the other bands migrated towards anode. The K1 band was similar to the J1 band of C. mos chata in their eletcrophoretic mobilities. The K4 band of C. maxima "Butter cup" was weaker than those of the other forms. No differences among C. maxima forms, "Butter cup," "Hoko-aokawa-amaguri," and "Delicious," could be found in the eletcrophoretic mobilities of their esterases as shown in Figs. 1 and 2. The bands of C. maxima forms were distinctly different from those of $C$. moschata forms, excepting a band migrating towards cathode. In various forms of C. pepo, eight bands were discriminated and designated as L1 L8. The L1 and L2 bands also migrated slowly towards cathode. The L2 band was slower in migration than the L1 band. The other bands migrated towards anode. Distinct

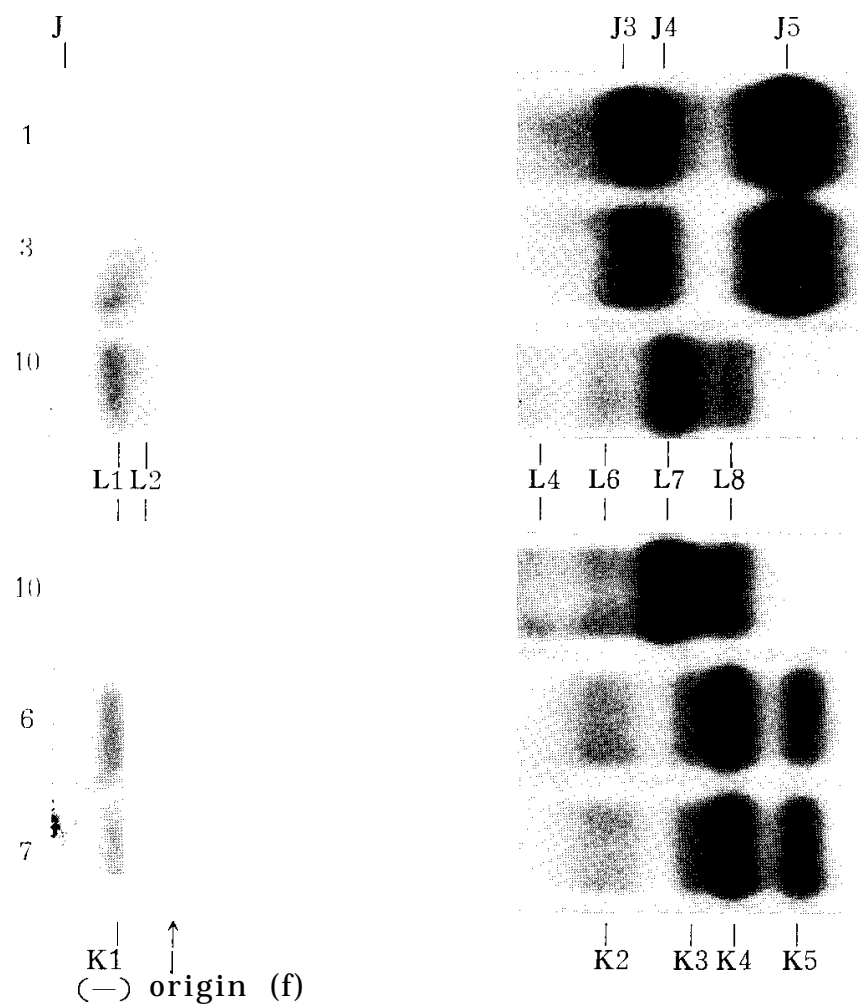

Fig. 1. Photograph of esterase zymograms showing the comparison of various esterase patterns of typical forms in the 3 species, C. moschata, C. maxima and C. pepo. 1) C. moschata "Shiro-kikuza." 3) C. moschata "Hyuga No. 14." 10) C. pepo "Pumpkin." 6) C. maxima "Hoko-aokawa-amaguri." 7) C. maxima "Delicious." 
differences in esterase composition were found among five different forms of $C$. pepo, as shown in Fig. 3; the L2, L3, L6, L7 and L8 bands were detected in C. pepo "Kinshiuri" (Vegetable Marrow), and the L1, L4, L5, L6 and L7 bands were detected in "Nishiki-kanro" and "Table Queen." In C. pepo "Pumpkin" and "Large Pumpkin," the L1, L2, L3, L4, L6, L7 and L8 bands were detected. Moreover, an immobile band was found in all the forms of C. pepo, (analysis of this immobile band was reserved in the present experiment). The L6 and L7 bands were detected in all the five forms of $C$. pepo.

In these comparative patterns of esterases, it is noticeable that "Kinshi-uri" (Vegetable Marrow) has the L2 and L8 bands, but has not the L1, L4 and L5 bands, in contrast to the fact that "Table Queen" and "Nishiki- kanro" have the L1, L4 and L5 bands, but not the L1 and L8 bands, and furthermore "Pumpkin" and "Large Pumpkin" pos-

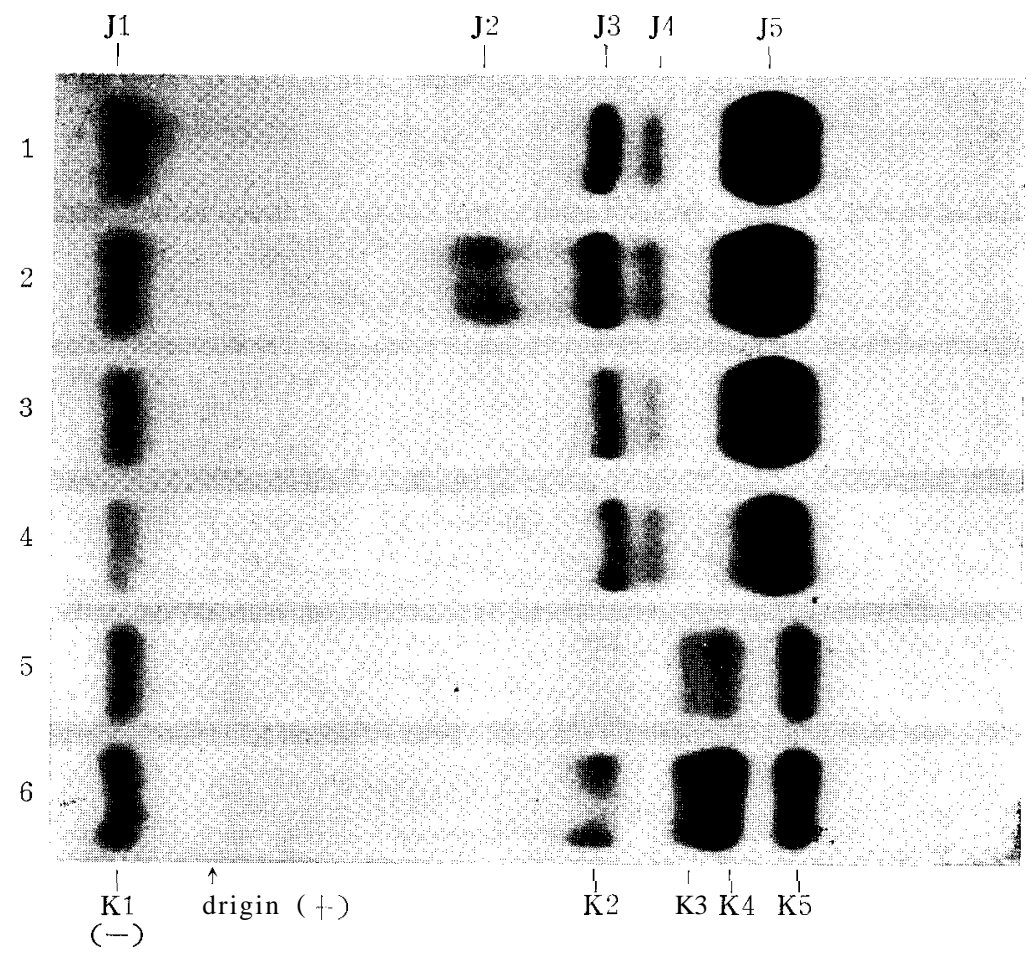

Fig. 2. Photograph of esterase zymograms showing the comparison among various esterase patterns in different forms of C. moschata and of C. maxima. 1) C. moschata "Shiro-Kikuza." 2) C. moschata "Aizuwase." 3) C. moschata "Hyuga No. 14." 4) C. moschata "Mike-kado." 5) C. maxima "Butter cup." 6) C. maxima "Hoko-aokawa-amaguri." 
sess those specific bands which are contained in both of "Table Queen" and "Nishiki-kanro", excepting the L5 band. Accordingly, the L2 and L8 bands seem to be characteristic of "Kinshi-uri" (Vegetable Marrow), while the L1, L4 and L5 bands seem to be characteristic of "Table Queen" and "Nishiki-kanro." These findings suggests that the different forms of C. pepo could be devided into three groups. That is 1) Vegetable Marrow group, 2) Table Queen group, and 3) Pumpkin group. The forms of the Table Queen group were highly cross-compatible with the forms of Vegetable Marrow group. In view of their cross-compatibility and different compositions of esterases, it could be estimated that the relationships between Table Queen group and Vegetable Marrow group will be on a quite similar level with the intra-genomic differences among Brassica oleracea var. botrytis and var. capitata (Eguchi and Matsui, 1969). As mentioned above, the array of the esterase bands of Pumpkin group was found to be composed of the bands which are present in both of Vegetable Marrow group and Table Qneen group. This finding suggests that there is a closer relationship between the Pumpkin group and either of the

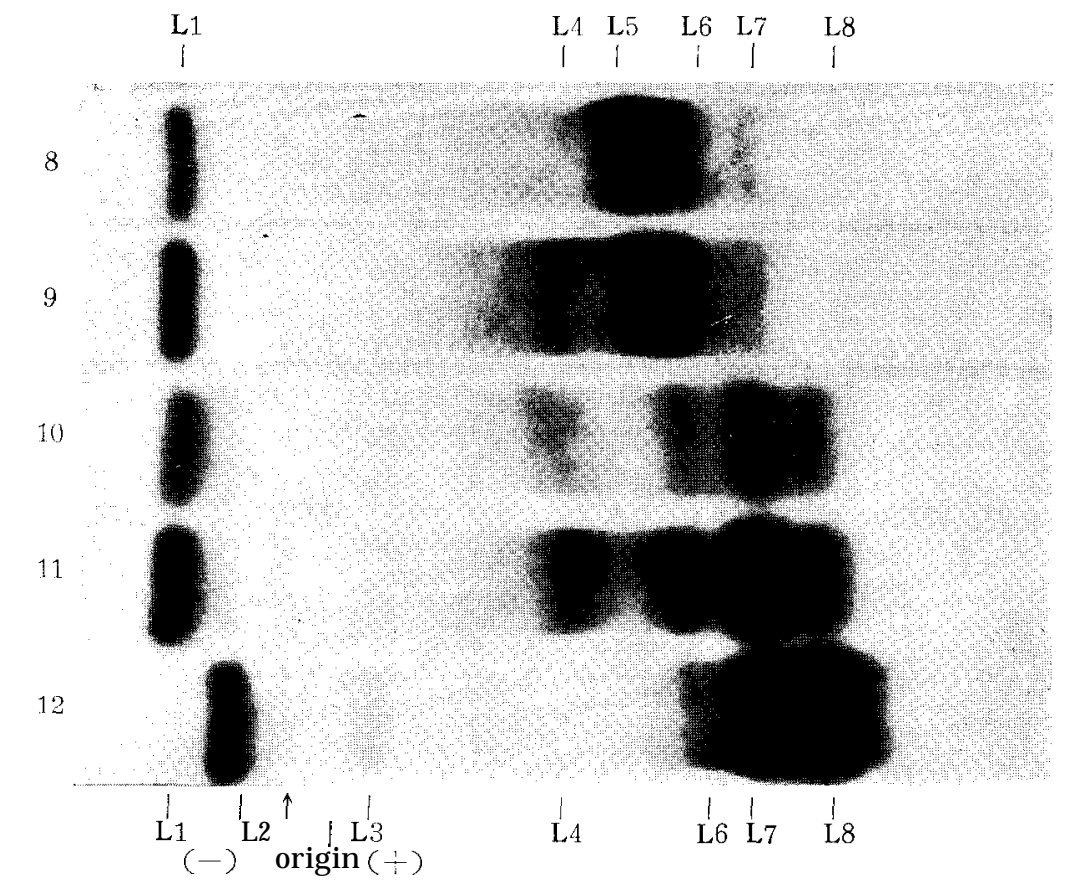

Fig. 3. Photograph of esterase zymograms showing intra-specific differences within C. pepo. 8) C. pepo "Nishiki-kanro." 9) C. pepo “Table Queen." 10) C. pepo "Pumpkin." 11) C. pepo "Large pumpkin." 12) C. pepo "Kinshi-uri." 
two groups than betweenthe Table Queen group and Vegetable Marrow group. In other words, the Pumpkin group seems to be intermediate between the Table Queen and Vegetable Marrow groups. Such heterogeneous composition of esterases, as observed in the Pumpkingroup, has been found in certain heterozygote strain of Drosophila melanogaster : Wright (1963) reported that a homozygote strain of D. melanogaster with Est $6^{\mathrm{s}} /$ Est $^{\mathrm{s}}$ has the esterase band $6 \mathrm{~S}$, and the other homozygote strain with Est $6^{\mathrm{F}} /$ Est $6^{\mathrm{F}}$ has the esterase band $6 \mathrm{~F}$, while Est $6^{\mathrm{S}} /$ Est $^{\mathrm{F}}$ heterozygote has both of the esterase bands, $6 \mathrm{~S}$ and $6 \mathrm{~F}$.- Individual genes designated as Est $6^{\mathrm{S}}$ and $\boldsymbol{E s t}^{\mathrm{F}}$, are responsible for formation of the esterase bands,

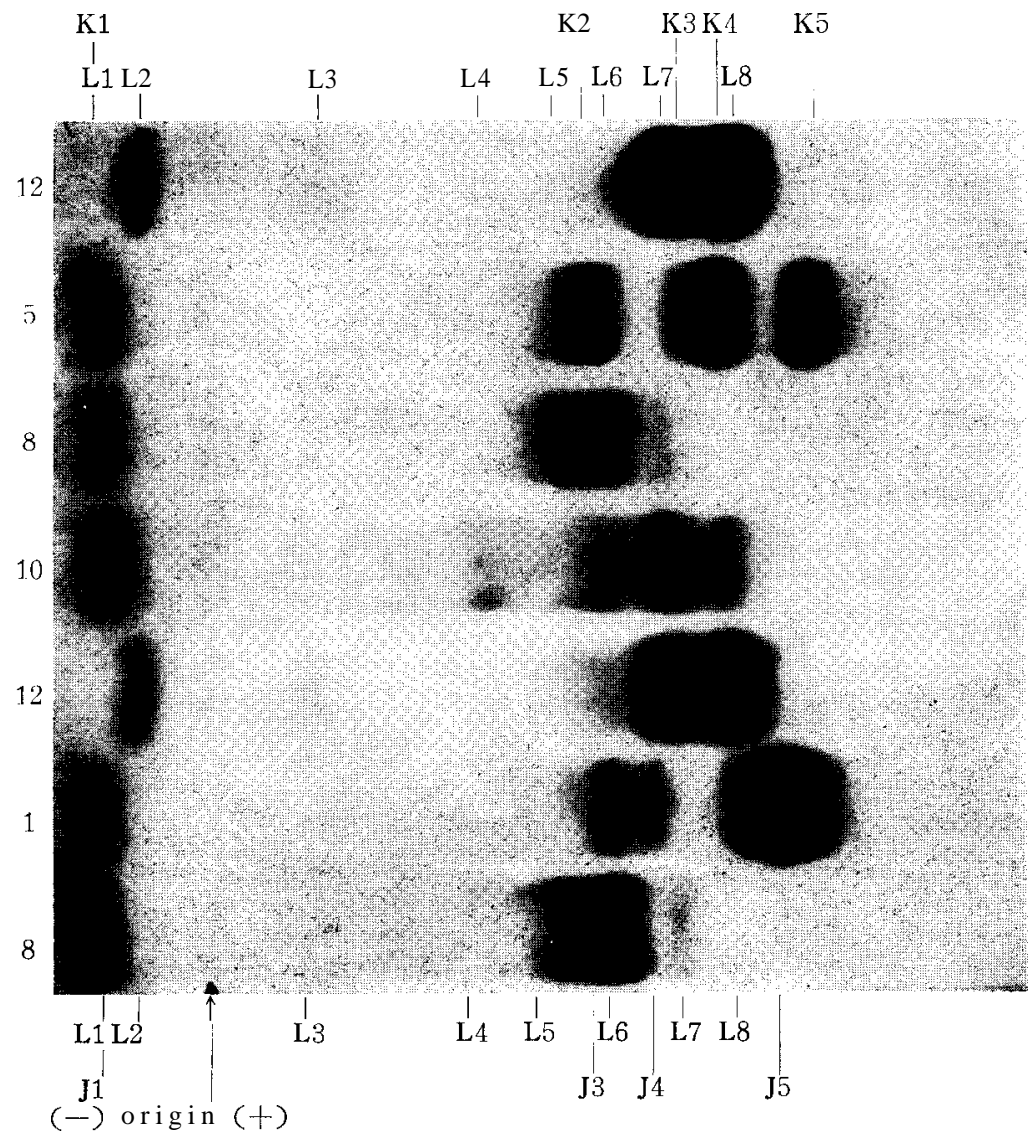

Fig. 4. Photograph of esterase zymograms showing comparisons of various esterase bands in C. pepo with those in other Cucurbita species. 12) c. pepo "Kinshi-uri." 5) C. maxima "Butter cup." 8) C. pepo Nishiki-kanro." 10) C. pepo "Pumpkin." 1) C. moschata "Shirokikuza." 
$6 \mathrm{~S}$ and $6 \mathrm{~F}$, respectively. Similar situation in the esterase composition of heterozygote strains has been observed by many workers in various species of animals. So that, the following deduction could be made from the above findings in the Pumpkin group : The Pumpkin group might be heterogeneous forms which have been synthesized by the cross between the Vegetable Marrow and Table Queen groups, through the evolutionary processes in nature, or artificial forces in breeding of those cultivars.

As shown in Fig. 2, the esterase bands in C. pepo appeared in their migrations to be close to the bands of the other species, For the purpose of comparing the electrophoretic mobilities of the bands of C. pepo with those of the other Cucurbita species in some details, the esterase zymograms for the diverse forms of C. pepo, C. maxima and of C. mos chata were prepared side by side on the same gel plate in the overlapping tests. The typical zymogram is shown in Fig. 4. The J1, K1 and L1 bands, migrating towards cathode, were similar in their mobilities. The L5 band characteristic of the Table Queen group in C. pepo was slower in migration than the $\mathrm{K} 2$ band of $\mathrm{C}$. maxima and the J3 band of C. moschata. The L6 band of C. pepo moved slightly faster than the J3 band of $\mathrm{C}$. moschata and the $\mathrm{K} 2$ band of $\mathrm{C}$. maxima. The $\mathrm{K} 2$ band moved more or less slower than the J3 band as shown in Fig. 4. The L7 band of $C$. pepo moved somewhat slower than the K3 band of C. maxima, and moved faster than the J4 band of C. moschata. The L8 band moved faster than the K4 band of C. maxima, and slower than the J5 band of C. moschata. That is, the L5, L6, L7 and L8 bands in the forms of C. pepo were distinctly different in their electrophoretic mobilities from the bands in the other Cucurbita species. Accordingly, excepting a band migrating towards cathode, distinct differences among those three species were found in the electrophoretic mobilities of their esterases. Yamane $(1952,1953)$ reported that 17.6 is the frequency of bivalents per a meiotic cell in the $\mathrm{F}$, hybrids raised by the reciprocal crosses between C. maxima and C. moschata. Hayase (1957) reported that the most frequent meiotic configurations in $F_{1}$ hybrids between $C$. maxima and C. pepo, are (4-10) I $\div$ (15-20) II $\dashv$ (O-l) III. While, Weilung (1956) has also made similar studies on the species hybrids in Cucurbita. and suggested that the species in Cucurbita are the secondary polyploid with basic number of $n=10$, and has further proposed that C. pepo, C. mixta, C. maxima and C. moschata have identical genome pairs, i. e., AABB. The results of present experiment could not support the identical genome constitution of AABB in C. maxima, C. pepo and C. moschata; if all the 3 species have the identical genome constitution, those species would possess some esterase bands in common. However, there were distinct differences in esterase patterns among those species, The 
esterase bands detected in the present experiment were listed in Table 2. The present results agree with the cytogenetical evidences obtained by Hayase (1957), i. e, the meiosis in F, hybrid between C. maxima and C. pepo is irregular. In view of these results, it could be estimated that the relationships among typical species, C. moschata, C. maxima and C. pepo is on a similar level with inter-genomic differences in Brassica described in the previous paper (Eguchi and Matsui, 1969).

Table 2. Esterase composition in cotyledonary seedlings of Cucurbita species.

\begin{tabular}{|c|c|c|c|}
\hline Species & Horticultural variety & \multicolumn{2}{|c|}{ Esterase band detected } \\
\hline C. moschata & Shiro-kikuza & J3, J4, .J5 & \\
\hline " & Aizu-wase & JI, J2, J3, J4, J5 & \\
\hline " & Hyuga No. 14 & J3, J4, J5 & \\
\hline C. maxima & Butter cup & $K 1(=\mathrm{J} 1), \mathrm{K} 2, \mathrm{~K} 3, \mathrm{~K} 4, \mathrm{~K} 5$ & \\
\hline " & Hoko-aokawa-amaguri & $K 1(=\mathrm{J} 1), \mathbf{K} 2, \mathbf{K} \mathbf{3}, \mathbf{K} 4, \mathrm{~K} \mathbf{5}$ & \\
\hline " & Delicious & $K 1(=\mathrm{J} 1), \mathrm{K} 2, \mathrm{~K} 3, \mathrm{~K} 4, \mathrm{~K} 5$ & \\
\hline C. pepo & Nishiki-kanro & $L 1(=\mathrm{J} 1=\mathrm{K} 1)$ & L6, L7 \\
\hline " & Table Queen & $L 1(=\mathrm{J} 1=\mathrm{K} 1)$ & L6, L7 \\
\hline$\prime \prime$ & Pumpkin & $L 1(=\mathrm{J} 1=\mathrm{K} 1), \mathrm{L} 2, \mathrm{~L} 3, \mathrm{~L} 4$, & 16, L7, L8 \\
\hline " & Large Pumpkin & $L 1(=\mathrm{J} 1=\mathrm{K} 1), \mathrm{L} 2, \mathrm{~L} 3, \mathrm{~L} 4$, & L6, L7, L8 \\
\hline " & $\begin{array}{l}\text { Kinshi-uri } \\
\text { (Vegetable Marrow) }\end{array}$ & L2, L3 & L6, L7, L8 \\
\hline
\end{tabular}

N.B. Italic types show the band with stronger intensity. Bold-faces show the band with the strongest intensity.

\section{Summary}

For the purpose of biochemical approach towards taxonomic and phylogenetic inquiries in the genus Cucurbita, esterase compositions in the seedlings of various forms of Cucurbita moschata, C. maxima and C. pepo were analyzed by the zymogram, and following results were obtained.

1) The distinct differences among C. moschata, C. pepo and C. maxima were observed in the electrophoretic mobilities of their esterases. From the result of previous experiment on Brassica species (Eguchi and Matsui, 1969), it could be estimated that there are inter-genomic differences among those 3 species.

2) The differentiations within C. pepo were more significant in extent than those within C. moschata or C. maxima.

3) The forms of $\mathrm{C}$. pepo could be divided into 3 groups, such as the Table Queen, Vegetable Marrow, and Pumpkin groups, 
4) Pumpkin group seems in its esterase patterns to be intermediate between the Table Queen and Vegetable Marrow groups. That is, an array of esterase bands in the Pumpkin group was found to bc composed of both of the bands present in two other groups. This fact suggest that the Pumpkin group might have been arisen through hybridization between the Vegetable Marrow and Table Queen groups.

\section{Acknowledgment}

The authors wish to cxpress their sincerest appreciation to Emer. Professor (Kyushu University) Dr. E. Fukushima for his valuable guidance. The authors' thanks arc due to Emer. Professor (Kyushu University) II. Itoh for his valuable advices. Many thanks arc given to Mr. Y. Kondo for supplying the material seeds.

\section{Literature cited}

1) Eguchi, II., and T. Matsui, 1969 Relationships between genome constitution and esterase composition in Brassica. Jour. Fac. Agric. Kyushu Univ. 15 (3) : 17.

2) Fukushima, E., T. Matsui, and H. Eguchi, 1968 Phylogenetic studies on Brassica species by means of serological method. Jour. Fac. Agric. Kyushu Univ. 14 (3): 341.

3) Hayase, H., 1957 Studies on Cucurbita-crosses XI : Cytogenetical studies on interspecific hybrids of C. maxima X C. pepo. Res. Bull. Hokkaido Natl. Agric. Sta. 72: 48 (in Japanese, English summary).

4) Hunter, R.L., and C.L. Markert, 1957 IIstochemical demonstration of enzymes separated by zone electrophoresis in starch gels. Science 125: 1294.

5) Ogita, Z., 1962 Genetico-biochemical analysis on the enzyme-actives in the house fly by agar-gel electrophoresis. Jap. Jour. Genet. 37: 518.

6) Weilung, F., 1959 Genomanalytische Untersuchungen bei Kurbis (Cucurbitu L.). Zuchter 29: 161.

7) Wright, T. R. F., 1963 The genetics of an esterase in Drosophila melunoguster. Genetics 48: 787.

8) Yamane, Y., 1952 Studies on species hybrids in the genus Cucurbitu. I, C. maxima X C. moschata and its reciprocal cross. Rep. Kihara Inst. Biol. Res. (Seiken Ziho) 5: 94.

9. Yamane, Y., 1953 Studies on species hybrids in the genus Cucurbita. II, F hybrids of C. moschutu and C. maxima. Rep. Kihara Inst. Biol. Res. (Seiken Ziho) 6: 112 . 